\title{
ANTECEDENTES RELATIVOS AL DESARROLLO INMOBILIARIO EN CHILE
}

\author{
Roberto Medina Infante \\ Profesor de Práctica Forense \\ Universidad Católica del Norte, Coquimbo
}

En primer término quiero agradecer la invitación de la Universidad de Guanajuato a nuestra Escuela de Derecho de la Universidad Católica del Norte de Chile, que permite compartir con ustedes mis apreciaciones acerca de la forma en que nosotros como país, hemos enfrentado las necesidades de desarrollo inmobiliario de diversos sectores.

Deseo iniciar mi exposición transmitiéndoles el más caluroso mensaje de amistad de nuestra Escuela de Derecho y, en especial, de Luz María Reyes Santelices, Directora del plantel.

Ocasiones como éstas contribuyen a mejorar nuestra relación, más aún, tratándose de personal e instituciones que persiguen el propósito común de encontrar fórmulas para acelerar el desarrollo de sus respectivos pueblos, en un ambiente de respeto y libertad de emprender.

Se me ha solicitado exponer sobre el tema Antecedentes relativos al desarrollo inmobiliario en Chile.

Para ir de lo mayor a menor cumplo con hacerles presente que desde hace varios años la Escuela de Derecho, sede Coquimbo, de la Universidad Católica del Norte me ha honrado entregándome la cátedra "Estudio de Títulos", inserta dentro del ramo "Práctica Profesional".

El "Estudio de Títulos" tiene por objeto el análisis de la documentación que da protección jurídica a los derechos de propiedad, entre los cuales están los que recaen sobre bienes raices; por ello, necesariamente debe tratarse en clases el aspecto inmobiliario ya que, preferentemente, pero no exclusivamente, la ponderación de la legalidad de la documentación es prevalente en lo que se refiere a éstos últimos.

Como el "Estudio de los títulos" comprende el examen de la prescripción, éste abarcará un lapso de tiempo mayor o menor, de acuerdo al título o razón originaria del derecho del titular.

Esta mayor o menor retroactividad que comprenderá la ponderación de los antecedentes se explica porque en nuestro país se sigue el sistema registral a través del Conservador de Bienes Raíces y con ello, la historia de la propiedad raiz. Con todo, la aplicación de toda la normativa de los títulos adquisitivos del dominio, (derivados del 
Derecho Romano), tiene abundantes excepciones que, o establecen sistemas excepcionales o reducen los plazos de prescripción. Un buen ejemplo de ello fue la Ley de Reforma Agraria por la cual el dominio entregado por la "Corporación de la Reforma Agraria", "CORA", era originario de tal manera que derechos anteriores tales como dominio, gravámenes, arrendamientos y otros, quedaban suprimidos para su estudio desde el momento de la expropiación, dando a los interesados la posibilidad de hacerlos valer sobre los montos consignados.

A partir de las grandes reformas estructurales hechas por el Gobierno Militar que tuvo a su cargo la conducción del país desde 1973 hasta 1990 y, especialmente, el cambio de mentalidad respecto del "derecho de propiedad", "sistema económico", "estímulo a las inversiones", "reglas claras y estables", "libertad de precios y de comercio", "subsidiariedad del Estado", "políticas de apertura al exterior", "liberalización de las tasas de interés". "reforma previsional" y otras, el mercado en bienes raíces, especialmente, el relacionado con la vivienda, comenzó un fuerte desarrollo que logró revertir la creciente tendencia deficitaria que mostraba la inversión inmobiliaria.

De allí que esta breve introducción sirva para justificar los aspectos que me permitiré tratar en este trabajo y que son:

1.- Historia de la actividad inmobiliaria en Chile;

2.- Situación legal actual;

3.- Perspectivas futuras; $y$

4.- Apoyo legal-administrativo al derecho de propiedad.

Trataremos estos aspectos siguiendo el mismo orden reseñado:

\section{1.- ASPECTO HISTÓRICO DE LA ACTIVIDAD INMOBILIARIA EN CHILE:}

Mirando hacia atrás, podemos observar que todos nuestros países han organizado sus sistemas inmobiliarios incurriendo, en mayor o menor medida, en reglas del juego que han resultado atentatorias contra un sano desenvolvimiento del sector. Sin establecer orden de importancia en cuanto a sus efectos, los siguientes factores han influido negativamente en el pasado en Chile y América Latina:

a) En relación a la vivienda se le ha dado una importancia sólo como bien físico, generador de servicios para personas, (protección, abrigo, seguridad y privacidad), olvidando las propiedades financieras, (liquidez, renta y plusvalía);

b) La desconección del mercado inmobiliario en relación a los mercados de capitales y financiero, en general, amparando su desarrollo bajo instituciones de giro exclusivo y reglamentaciones especiales, que tan pronto dejan de serlo, conducen a una crisis sectorial; a esto se suma, la carencia de instrumentos financieros adecuados de largo plazo; 
c) La actuación directa y discrecional del Estado en lo inmobiliario e incluso en la construcción, (con secuelas de ineficiencia, baja orientación a los clientes y externalidades negativas, competencia desleal para el sector privado, etc.);

d) La insuficiencia de canales para la participación del sector privado en la provisión de financiamiento y de infraestructura, lo que ha limitado artificialmente la demanda financiada y oferta de suelo, satisfactoriamente urbanizado;

e) La extensa y variada gama de subsidios ocultos, que distorsionan el sistema de precios, en vez de aquellos incentivadores y/o correctores;

f) Tasas de interés reales negativas o excesivamente bajas, a veces en perjuicio de los ahorrantes, especialmente en períodos inflacionarios;

g) Políticas permisivas frente a los deudores, principalmente por razones políticas;

h) Las distorsiones en el mercado de arriendo de viviendas y, por último;

i) Los problemas con los registros de propiedad, que se traducen en un alto costo y en largo tiempo para operaciones relacionadas con el dominio y/o garantías.

Cabe señalar que todo esto se dio frecuentemente, en un ambiente de inestabilidad y desequilibrio macroeconómico, particularmente en períodos de alta inflación, especialmente a los inicios de la década del 70.

En definitiva, las erradas políticas inmobiliarias nos han llevado a un déficit estimado en América Latina de más de 28 millones de unidades, que año a año se incrementa, con la excepción de sólo dos países que han logrado revertir esta negativa tendencia.

En este sentido, vale la pena intercambiar ideas y comentarios acerca de la experiencia chilena, para observar los errores cometidos, así como los aciertos que han ayudado en el desarrollo de la actividad y el sector privado.

No quiero aburrirlos con un recorrido histórico detallado, por ello voy a referirme más adelante sólo a algunos hitos en el proceso de cambios y modernización de nuestra economía chilena que nos ha permitido tener logros en esta área.

Durante la primera mitad de este siglo la participación del Estado fue determinante en el desarrollo del sector.

En efecto, desde los años 30 las políticas aplicadas correspondieron a las recetas keynesianas, posteriormente recogidas por la CEPAL, esto es, una política de sustitución de importaciones, con gran injerencia estatal en aspectos básicos tales como precios, tasas de interés, tipos de cambio, créditos y tributación, en conjunto con la creación de una vasta estructura de organismos públicos concebidos para controlar la actividad productiva. La aplicación de estas políticas, en conjunto con los bajos niveles de desarrollo económico, significaron en Chile la construcción, entre 1906 y 1953, de 
aproximadamente 79.000 viviendas, sin incluir aquellas que fueron financiadas exclusivamente por particulares, lo que representa un exiguo promedio de 1.950 viviendas por año. En el mismo período, la población se duplicó y el déficit habitacional creció enormemente, lo cual refleja la incapacidad del esfuerzo estatal en tanto no considere mecanismos para atraer capital privado al sector. Más aún, a nivel del país, la aplicación de estas políticas provocó el recrudecimiento del flagelo inflacionario a niveles inéditos, lo cual requirió un severo ajuste monetario entre 1956 y 1958.

El Estado Chileno tradicionalmente ha sido impulsor de planes de construcción de viviendas; posee una larga tradición en este campo. Los primeros planes de viviendas sociales se remontan al año 1906 , en que se dicta la ley que crea los llamados Consejos de Habitaciones para Obreros. Con posterioridad se ha ido, a través de planes respaldados por sistemas de financiamiento y por leyes especiales, dando respuestas acordes con el desarrollo económico del país y con las necesidades de contrarrestar los déficits habitacionales.

Se incentivó a las Cajas de Previsión para que, con los fondos de pensiones, construyeran viviendas las que eran vendidas a los imponentes sin cláusulas de reajustabilidad; es fácil comprender que un sistema así colapsó frente al hecho económico de la inflación, ya que los adquirentes terminaron pagando valores que no reflejaban los verdaderos de lo adquirido. Por lo demás, este sistema de la falta de reajustabilidad era una característica del sistema económico chileno, especialmente del bancario y comercial, en los cuales las operaciones a plazo normalmente daban rentabilidades negativas. Esto asociado a una óptica católica que, en ese entonces, miraba con recelo toda reajustabilidad del capital.

\section{Ley Pereira}

Dictada en el año 1941, facilitó la construcción de viviendas para la clase media, principalmente funcionarios de la administración pública, desarrollando las emergentes comunas del sector Oriente de Santiago; con su apoyo se construyeron aproximadamente 62.000 viviendas.

\section{Decreto con Fuerza de Ley № 2}

Este pobre desempeño para solucionar el déficit de viviendas estimuló al recientemente electo Presidente de la República, don Jorge Alessandri, al estudio de un Plan Habitacional que llevó la promulgación, en 1959, del Decreto de Fuerza de Ley № 2, (conocido como D.F.L. 2), que consideró la aplicación de diversas franquicias tributarias, principalmente de los impuestos a la renta, territorial y de herencias y donaciones, para las viviendas de superficie edificada no superior a los 140 metros cuadrados más un sistema de exenciones tributarias, de definición de estandares y normas para viviendas económicas y sistemas de financiamiento de la demanda, lo que produjo el segundo crecimiento de las comunas del sector Oriente y el desarrollo de las del sur, vecinas a la de Santiago. 
La Ley Pereira, el D.F.L. 2, el Subsidio a la Marginalidad Habitacional, el Subsidio General Unificado u otros, que son las formas de identificar estos planes, son fácilmente reconocibles al observar el desarrollo del área metropolitana.

Esta labor fue desarrollada principalmente a través de los programas de viviendas sociales de la "Corporación de la Vivienda", ente estatal dependiente del Ministerio de Vivienda y Urbanismo y de las "Asociaciones de Ahorro y Préstamo", creadas especialmente para este fin, estas últimas que desvirtuaron el sistema captando a corto plazo, prestando a largo.

Este período se desarrolla entre los años 1959 y 1978; con posterioridad el D.F.L. 2 se sigue aplicando en sus aspectos normativos y estandarizadores, perdiendo interés sus ventajas tributarias y de financiamiento.

Durante este período, otros aspectos inmobiliarios, tales como "las concesiones", no fueron considerados.

\section{2.- SITUACIÓN ACTUAL DE LA ACTIVIDAD INMOBILIARIA}

En primera instancia y a modo de rápido diagnóstico intentaré entregar las características de cada uno de los sectores que componen este mercado y de cómo cada uno de éstos ha influido, influyen y deberían influir en la definición de las políticas habitacionales de nuestro país.

He considerado una buena forma de análisis separar el caso de aquellas viviendas en las que el Estado ayuda a su adquisición a través de un subsidio a la demanda de aquellas viviendas de mercado adquiridas por el sector privado en forma independiente, el que ha podido desarrollarse normalmente gracias a tres factores determinantes:

- Las empresas que han sido capaces de entregar al mercado los productos que éste les ha requerido.

- Las instituciones de crédito, que han proporcionado diversas alternativas de financiamiento a largo plazo.

- Por último, ha existido una demanda privada que ha querido y ha podido comprar las viviendas.

En este mercado el Estado cumple sólo con un rol regulador.

\section{Situación del Desarrollo Urbano en Chile}

Hemos considerado de interés analizar con mayor detalle el efecto producido por el desarrollo de planes habitacionales masivos de viviendas sociales en el crecimiento de las ciudades, debido a que éstos constituyen una de las principales causas del desarrollo descontrolado de ellas y la mala calidad de vida de sus usuarios. 
La voluntad de dar una vivienda a cada familia es una realidad para nuestro país y para la mayoría de los países de América Latina y es, además, una necesidad impostergable, debido al gran déficit habitacional y a su constante crecimiento.

Los gobiernos nacionales sienten esta obligación y la urgencia por satisfacerla, lo que ha llevado a superponerla a la de lograr un desarrollo integral y armónico de las ciudades con planificaciones territoriales eficientes y coordinadas, amenazando seriamente su sustentabilidad futura.

Por otra parte, la cantidad de recursos disponibles alcanzan para solucionar con dificultad sólo una parte del problema, teniendo siempre la primera prioridad la necesidad de construir viviendas por sobre la del desarrollo urbano sustentable.

Existe en el país una larga experiencia en diseño y construcción de viviendas sociales, cuya aplicación actual es bastante exitosa. Pero existe, al mismo tiempo, una situación permanente de deterioro de la calidad de vida de sus habitantes, por la insuficiencia de equipamiento urbano disponible y por la falta de una planificación y administración que mejore la operación de la ciudad y garantice su futuro desarrollo.

La mayor parte de las ciudades importantes de Chile se localizan en valles, ocupando terrenos planos con buena aptitud agrícola, con amplias áreas residenciales constituídas principalmente por edificaciones en uno o dos pisos.

Difieren de esta descripción algunas ciudades puertos que por su localización en el borde costero se han debido adaptar a otro tipo de topografías. En todo caso, vecino a estos puertos, casi siempre encontramos un núcleo urbano desarrollado en la forma descrita anteriormente.

El desarrollo de estas ciudades se ha producido por el aumento permanente de las zonas urbanizadas mediante la incorporación de áreas periféricas, transformándolas de rurales en urbanas.

Esta situación se ha visto respaldada por "Planes Reguladores", que han ampliado permanentemente el límite de las Zonas Urbanizables, respondiendo a las exigencias del crecimiento poblacional y/o por el aumento de la demanda de mejores estándares habitacionales. Existe gran discusión si liberalizar o no la ampliación de las ciudades, para los efectos de disminuir el valor de los terrenos.

En Chile la solución de los problemas habitacionales, en su mayor parte se ha hecho en base a la construcción de viviendas unifamiliares con terrenos propios. Los edificios en altura, tradicionalmente se han destinado a oficinas y servicios. En Santiago, la capital, a pesar de haberse construido en este último tiempo un gran cantidad de edificios residenciales, aún es mayoritaria la construcción de viviendas unifamiliares.

Esto se atribuye a la idiosincrasia del chileno de todos los niveles sociales, que prefiere disponer en su vivienda de una porción de terreno propio que le permita disfrutar de un patio de su uso exclusivo. 
Políticamente ningún Gobierno, al diseñar sus planes habitacionales, ha decidido la opción de modificar esta tendencia.

Esta característica es tan notable que la ciudad de Santiago ha mantenido desde su fundación hasta la actualidad, una densidad habitacional casi constante. Contra el aumento de su población se ha respondido con un crecimiento de su área urbana.

Como resultado de lo anteriormente expuesto, se ha producido en nuestro país un crecimiento permanente y desmesurado de las áreas urbanizadas de las ciudades. Agreguemos a esto:

- Un sistema inadecuado de planificación y administración del ordenamiento territorial;

- Una preocupación exclusiva por la construcción de viviendas, postergando la parte de equipamiento, servicios y recreación;

- Y, al bajo monto de los recursos asignados para subsidiar la construcción de viviendas, que ha obligado a hacerlo en las zonas donde el valor del terreno tuviera la menor influencia en el precio final de ellas.

Podremos explicarnos entonces, por qué la ciudad que hoy tenemos, aparece aquejada por tan serios problemas y carencias en su funcionamiento, que afectan fuerte y directamente la calidad de vida de sus habitantes.

Por qué hacemos especial hincapié, en el desarrollo de estas áreas:

1. Por ser éstas las que comprometen la mayor cantidad de terrenos, donde el impacto de las obras realizadas es más definitivo, ya que los estándares constructivos han sido definidos para tener un vida útil superior a los 60 años;

Esta condición se ve acrecentada por la exigencia de que estas viviendas cuenten con estructuras asísmicas a todo evento, que las hacen aún más permanentes, estableciendo ciclos muy extensos para la disposición de terrenos para renovación urbana;

2. Porque las acciones de recuperación o renovación se encuentran con un mayor grado de complicación, por afectar a una gran cantidad de propietarios, producto de la sucesiva subdivisión del suelo;

3. Por ser las que plantean relaciones y dependencias más complejas con las otras actividades que se desarrollan en la ciudad, como son la integración con la industria, recreación y servicios; y

4. Por la incidencia directa en el mayor costo de funcionamiento de la ciudad, que significa una planificación errada de ellas. Este mayor costo es pagado por todos los usuarios y su efecto mas notorio es el mayor tiempo empleado en el traslado a los lugares de trabajo y de educación. 


\section{Efectos negativos en el desarrollo de la ciudad}

Si consideramos la localización de los terrenos en que se han desarrollado los programas habitacionales de las viviendas mas económicas, su relación con las principales áreas donde se ubican las fuentes de trabajo, salud, educación y servicios, podemos constatar que se han producido los siguientes efectos:

1. Colapso de las estructuras viales previstas en los planes reguladores para servir estas áreas;

2. Falta de dotación de equipamientos públicos y áreas verdes, acordes a las necesidades de los numerosos habitantes que allí se localizaron. Estos deben trasladarse a grandes distancias para acceder a ellos;

3. La radicación casi definitiva de los propietarios, a causa de la rigidez del sistema de uso y disposición de las viviendas, que les impiden la posibilidad de venderlas o arrendarlas y poder cambiar así, su lugar de residencia, por razones de trabajo o de mejorías de estándar;

4. Costos mayores en la administración pública de la ciudad porque debe otorgar nuevos servicios de educación y salud pública, orden y seguridad y servicios municipales;

5. Mayores costos de implementación de los servicios públicos de urbanización al extenderlos ineficientemente hacia la periferia con reforzamiento hacia el centro de la ciudad;

6. Desincentivación y competencia desleal con la posibilidad de crecimiento por rehabilitación o remodelación de las áreas consolidadas;

7. Utilización de terrenos vecinos a las ciudades, que antes se destinaban a la producción agrícola. La recuperación de estas areas, es para nuestra realidad de país, imposible;

8. Las grandes distancias entre los lugares de residencia y los de trabajo se cubren mediante el uso de servicios de transporte público de baja calidad, productores de una alta contaminación acústica y atmosférica

Se ha detectado que los compradores de viviendas en las áreas céntricas renovadas, las eligen principalmente por las ventajas de cercanía al trabajo, que proporciona a la familia un gran ahorro de tiempo en el transporte;

9. Las urbanización de estos sectores, excluyó la ejecución de pavimentos permanentes en sus vías, transformándose estas en una de las mayores fuentes productoras de contaminación atmoférica por partículas que afectan a la ciudad y responsable del deterioro de la calidad de vida de los barrios formados;

10. Las necesidades de áreas de esparcimiento, de equipamiento y servicios públicos requeridos por estas nuevas poblaciones no fueron oportunamente satisfechas, 
transformándose en proyectos incompletos que afectan directamente al entorno natural y a la planificación territorial lógica y necesaria;

11. La baja densidad impide el desarrollo del equipamiento privado de servicios de buena calidad y por el contrario estimula el desarrollo de equipamientos marginales e informales;

12. Esta expansión obliga al Estado a extender sus servicios de seguridad, que por falta de financiamiento específico, crea zonas de alto riesgo de delincuencia y subversión;

13. Endurecimiento de grandes áreas urbanas, por la creación de un gran número de propiedades de predios muy pequeños, utilizados en la construcción de viviendas de bajo estándar, cuya posterior renovación se verá fuertemente entorpecida por la dificultad que significa aunar voluntades de venta colectiva que permitan contar con extensiones de terrenos para remodelación de tamaños interesantes que faciliten la configuración de nuevos barrios;

14. Este endurecimiento, se traduce también en fuertes restricciones a las posibilidades de diseño y ampliación de la estructura vial de la región, para lo cual será necesario expropiar a justo precio edificaciones, en lugar de suelo desocupado;

15. Alteración de los sistemas naturales de escurrimiento de aguas, al disminuir las superficies de absorción, lo que obliga a proyectar y construir costosas redes de alcantarillado de aguas lluvias; y

16. Sobre solicitación de redes viales de bajo estándar para dar acceso a nuevas áreas urbanas con deterioro prematuro de ellas, que obligan a invertir en reposición y mantención en forma permanente y anticipada.

\section{Sistemas de operación inmobiliaria:}

En lo que se refiere al financiamiento privado, existe una gran gama, especialmente para la vivienda.

En el cuadro anexo entregamos un análisis distinguiendo origen del financiamiento; hemos dividido este acápite en dos temas principales:

1.- De acuerdo a la forma de financiamiento de la obra; y

2.- Como se financia al adquirente.

\section{1.- De acuerdo a la forma de financiamiento de la obra:}

Toda obra puede tener un financiamiento emanado de los propios recursos del inversionista.

En caso que no lo tenga, existe un financiamiento público, destinado al rubro viviendas de menor valor, como una forma de lograr menores costos para los futuros 
adquirentes. Este sistema se gestiona a través del Servicio de Vivienda y Urbanismo, dependiente del Ministerio de la Vivienda.

Para obras de mayor envergadura, entre ellas viviendas, existe un expedito finaciamiento bancario, al cual se le llama "presupuesto por programa" esto es, que la institución financiera va entregando los recursos a medida del avance de obras, tomando como garantía el terreno y lo construído; esta modalidad de operación necesariamente requiere el estudio de los títulos para asegurar la transparencia de la garantía.

\section{2.- Como se financia al adquirente:}

En la segunda parte del cuadro se enuncia el financiamiento al usuario final.

En primer término, encontramos el financiamiento público.

No existe un financiamiento total con fondos públicos al adquirente de una vivienda. Si lo existe parcial, de acuerdo a algunas de las modalidades de subsidio que veremos a continuación:

\section{A.- Sistema de Subsidio Nacional Unificado}

Puesto en vigencia por D.S. № 188 del año 1978 y modificado posteriormente hasta llegar a la versión actual, contenida en el D.S. № 44 del año 1988, que permitió el desarrollo de las comunas de periféricas del área sur poniente y norte de la Región Metropolitana. Destinado al financiamiento de la demanda de viviendas sociales, cuyo precio de venta debe fluctuar entre los US\$10.000 y los US\$53.000.

El Estado en la actualidad entrega anualmente una cantidad de 25.000 subsidios cuyo monto unitario promedio es de US\$ 3.300 aproximadamente, que permite a los interesados comprar en el mercado viviendas financiadas y construidas por el sector privado.

El sistema ha facilitado la construcción de 135.000 viviendas en el período 19781993, ocupando una superficie bruta de 2.700 has. de terreno urbano en la Región Metropolitana.

El Gobierno, como "Política de Estado" ha querido incentivar el mercado inmobiliario; partió con "Subsidios a la oferta" para después hacerlo con "Subsidios a la demanda".

\section{B.- Subsidio a la marginalidad Habitacional}

Puesto en vigencia por el Decreto Supremo № 62 de 1984 y orientado a subsidiar la demanda de la población de más escasos recursos, para lo cual se determinó un estándar mínimo habitacional, denominado "Vivienda Básica". El Estado subsidia el $75 \%$ del valor de la vivienda y otorga un crédito hipotecario por un $15 \%$ a $20 \%$ de este valor a 20 años plazo. Los usuarios sólo aportan un ahorro equivalente a un $5 \%$ a $10 \%$ del valor de la vivienda. 
Este sistema ha sido desarrollado vía la contratación con empresas privadas, por parte del Estado, de la construcción de viviendas de $36 \mathrm{~m} 2$ aproximadamente, que cuentan con dos o tres dormitorios, estar-comedor, cocina y baño, en un terreno con urbanización básica. Su costo mínimo por unidad es de US\$ 5.700 , y se han construido en la Región Metropolitana, 150.000 viviendas a partir del año 1978, ocupando 3.200 has. de terreno urbano.

\section{C.- Sistema de Subsidio Especial para Trabajadores}

Regulado por el Decreto Supremo № 235 del año 1985, (iniciado en 1988), aporta la construcción de 15.000 viviendas anuales. Este sistema, por no requerir de maduración o permanencia del ahorro, ha sido muy eficiente, permitiendo la construcción de 41.000 viviendas de un valor promedio de US\$7.600, ocupando 720 has. de suelo urbano en la Región Metropolitana.

\section{D.- Lotes con servicios}

Consistentes en un terreno dotado con urbanización básica e instalaciones domiciliarias de agua potable, alcantarillado y electricidad y además la construcción, en $10 \mathrm{~m} 2$ aproximadamente, de una cocina y un baño.

La inversión considerada para este tipo de operación es de US\$3.100 por unidad y se han construido alrededor de 50.000 unidades a la fecha, utilizando una superficie de 1.060 has. de terreno urbano en la Región Metropolitana.

\section{D.- Viviendas Progresivas}

Sistema comenzado a aplicar a partir del año 1991, contempla la construcción de una primera etapa muy similar a la considerada para los lotes con servicio, más una etapa de crecimiento por cuenta el propietario al que se le otorga un financiamiento para realizarla. Se considera una inversión de US\$2.900 por unidad y se han construido 3.000 unidades de este tipo, ocupando una superficie de 65 has. urbanas en la Región Metropolitana.

Este sistema de operación, afortunadamente no ha sido de aplicación exitosa, ya que ha demostrado ser la mejor forma de producir un crecimiento deteriorante de la ciudad, al incorporar estándares muy bajos de calidad vivienda e incentivar la construcción espontánea e inorgánica.

Los resultados de la aplicación de todos estos programas, salvo el ya indicado, no pueden haber sido más exitosos; en efecto, el país ha logrado construir más de 1.500 .000 viviendas en 52 años, ha disminuido su déficit habitacional en forma considerable y ha desarrollado una industria constructora de viviendas sociales de alto nivel de productividad.

Pero esta es sólo una cara de la moneda, pues tal como lo enunciamos anteriormente, esto se ha traducido también en el crecimiento desmesurado del área urbana, en la localización de grandes zonas residenciales periféricas, lejanas o desconocidas de 
aquellas en que se ubican las fuentes de trabajo, los servicios y los centros educacionales y de salud.

Estos importantes programas de construcción de viviendas sociales, comprometieron la inversión de casi la totalidad de los recursos de que disponía el Ministerio de Vivienda y Urbanismo para el desarrollo integral de estas nuevas áreas urbanas, quedando la ejecución de equipamientos, áreas verdes y servicios, postergados para la oportunidad en que se dispusiera de mayores recursos.

Las limitaciones en los precios asignados a los lotes con servicios, las viviendas progresivas y básicas, obligaron a utilizar terrenos cuyo valor no incidiera en forma considerable en el costo final de la vivienda. Estos terrenos correspondían a paños periféricos de carácter agrícola, que contaran con factibilidades sanitarias, viales y de dotación eléctrica mínima.

Este aspecto afecta principalmente al desarrollo del sector de viviendas de más bajo costo, ya que al no ser factible su financiamiento al largo plazo por el sector privado, queda restringido sólo al número de operaciones que cuentan con financiamiento estatal a través del Banco del Estado.

Cualquier iniciativa respecto de provocar la movilidad habitacional en este sector, deberá pasar por resolver este punto.

En este sentido consideramos positivo el desarrollo de una industria financiera no bancaria orientada al financiamiento de operaciones de bajo monto.

En cuanto al finaciamiento privado, encontramos interesantes alternativas en el mercado de capitales chileno.

\section{A.- Financiamiento directo del inversionista:}

Existen en el mercado inmobiliario entidades que tienen la capacidad económica de financiar ellas mismas las inversiones que hacen.

En estos casos se unen especialidades distintas que son la inmobiliaria, a veces la de construcción y la financiera.

Encontramos en el mercado este tipo de actividades unidas como grupo económico pero que operan como entidades independientes una de otras.

\section{B.- Créditos con letras hipotecarias:}

Este sistema permitió dar un impulso eficiente al tema inmobiliario y que se ha constituído en una de las alternativas más usadas por los adquirentes de viviendas particulares. Cuando un interesado desea adquirir un inmueble recurre a una institución financiera quién entrega hasta el $50 \%$ del valor de tasación de la propiedad, debiendo el interesado hacer un esfuerzo de, a lo menos, un $25 \%$. Existen el el mercado opciones de financiar este último porcentaje con préstamos complementarios. 
Aprobada la operación, se otorga la correspondiente escritura y el banco emite letras hipotecarias las que son entregadas al comprador, (en la práctica lo hace el ban$\mathrm{co}$ ), para ser colocadas en el mercado de capitales secundario, que las adquiere porcentajes sobre la par, a la par o bajo la par, lo que está relacionado con las tasas de interés vigentes. El adquirente de la vivienda debe pagar al banco y éste al inversionista que adquirió las letras, en sus respectivos vencimientos.

Esta operación se respalda con garantía hipotecaria y prohibiciones de gravar y enajenar y obliga también al estudio legal de los antecedentes.

No sólo operaciones de viviendas pueden financiarse con las "letras hipotecarias"; también hay préstamos para "usos generales", en los cuales se sigue el mismo sistema.

\section{C.- Créditos con mutuos hipotecarios:}

El sistema de "mutuos" persigue el mismo objetivo final que es el financiar operaciones inmobiliarias.

La diferencia principal se encuentra en la ausencia de las "letras hipotecarias". El "mutuo" es el prástamo de dinero.

Hagamos un paréntesis para hacer presente que, en definitiva el monto del cargo financiero es prácticamente igual, desde el momento en que todas estas operaciones van al mercado de capitales donde el inversionista buscará la mejor rentabilidad para su capital lo que se traducirá en que, entre las muchas opciones para invertir, elegirá la más rentable. En el caso de la letras hipotecarias, el adquirente, deseando una tasa de interés alta verá las que corresponden al documento, (que serán las pactadas para el crédito), y si no está conforme con ellas, aplicará una tasa de descuento que se traducirá en definitiva que el instrumento sea transado bajo, o sobre la par.

\section{D.- Arrendamiento de viviendas con promesa de compraventa:}

Después de una prolongada tramitación legislativa, en Diciembre de 1993 fue publicada la Ley que permitió el "arrendamiento de viviendas con promesa de compraventa". Esta nueva normativa legal crea un complejo sistema en el cual participan "la propietaria", es decir una empresa dueña de la vivienda que la arrienda a un "cliente" quién promete comprarla una vez transcurrido el plazo acordado. Para dar operatividad al sistema, se crearon las Administradoras de Fondos para la Vivienda, en las cuales los arrendatarios promitentes compradores depositan sus cuotas, (parte de las cuales van al pago del arriendo y parte a reunir el dinero para la compra futura), las Securitizadoras, que son las que adquieren los contratos de arrendamiento con promesa de compraventa de las "inmobiliarias", (propietarias) y los inversionistas institucionales. En otras palabras, en forma muy inteligente se ha coordinado el mercado inmobiliario con el financiero. Este sistema, de lenta partida, se ha estado consolidando. 


\section{3.- PERSPECTIVAS FUTURAS}

Como se ha podido observar, el tema "inmobiliario" abarca una multiplicidad de facetas; en nuestro país, especialmente en relación al mercado de viviendas, el sistema ha funcionado razonablemente bien pero, por supuesto, es una obra perfectible, especialmente, para ir entregando a la población mejores calidades de vida.

\section{Alternativa de Renovación Urbana}

Frente a la realidad perniciosa de desarrollo por extensión de la ciudad, se plantean las siguientes soluciones:

- La renovación y densificación de los sectores urbanos consolidados y una política de estímulo a la construcción de los terrenos eriazos disponibles al interior del radio urbano.

- Posibilitar la complementación de las áreas de extensión con planificaciones especiales, dirigidas a suplir las deficiencias de equipamiento y relación con el resto de la ciudad.

- Contar con una "Estrategia Regional de Planificación Territorial", coordinada con los distintos agentes que intervienen en la formación de la ciudad y definen su vocación y destino.

Esta estrategia debería considerar la creación de un sistema de polos y ejes de desarrollo, que permitan absorver el crecimiento de las ciudades, mediante la renovación urbana de los pequeños poblados ubicados a distancias aproximadas a los 50 kilometros de las grandes áreas urbanas. Las vías que los unan se transformarían en ejes donde se podrían localizar las fuentes de trabajo. Debe en todo caso impedirse la incorporación de los territorios de estos polos a las áreas urbanas de la gran ciudad.

Las limitaciones o inconvenientes que se presentan en nuestro país respecto de la aplicación de un proceso de esta naturaleza son:

1.- Las áreas consolidadas posibles de remodelar generalmente corresponden a sectores antiguos deteriorados, en los cuales existen una gran cantidad de propietarios, muchas veces sucesiones hereditarias, los que deben ponerse de acuerdo para lograr su venta. Muchas veces no cuentan con los títulos de propiedad saneados y la tramitación de ellos es lenta y burocrática;

2.- La superficies de los predios son pequeñas y para poder desarrollar operaciones de renovación con una masa crítica adecuada debe contarse con la posibilidad de comprar varios terrenos vecinos, lo que produce un aumento de precio, motivado por las expectativas que se crean al ir desarrollando la operación en el tiempo;

3.- La dotación de servicios sanitarios, de energía eléctrica, de comunicaciones, de vialidad y estacionamientos, sus conexiones con el resto de la ciudad, debe ampliarse a tal nivel, que probablemente una operación de renovación a gran escala obligaría a 
desestimar las existentes, debiendo construirse nuevas instalaciones trazadas por vías en pleno uso, con la consiguiente congestión y molestia para los vecinos;

4.- Obligación de modificar la tipología de las viviendas a construir, lo que implicaría asumir un mayor riesgo de comercialización y los futuros usuarios, entiéndase cambio de hábito en el uso de departamentos construidos en edificios en altura versus la tradicional costumbre de hacerlo en viviendas unifamiliares de uno o dos pisos;

5.- Riesgo de aumento congestión vehícular por incremento del parque automotriz residente;

6.- Posible incremento de la contaminación atmosférica por el aumento del número de servicios de movilización colectiva convergentes al centro de la ciudad;

7.- Reubicación de los actuales pobladores de los sectores a renovar, que generalmente son personas de mucha edad o de escasos recursos económicos, lo que les impide poder ser acreedores de un crédito de largo plazo para comprar la nueva vivienda.

Estos inconvenientes pueden ser superados con facilidad si se cuenta con una "Política nacional de Renovación Urbana" que contenga las herramientas e incentivos necesarios que la hagan operativa.

Entre las herramientas fundamentales deben considerarse las siguientes:

- Facultad de saneamiento del título de propiedad.

- Facultad expropiatoria, a justo precio, para solucionar casos críticos de bien común.

- Incentivos a las empresas que desarrollen proyectos de renovación.

- Sistema de financiamiento de la demanda, que incluya subsidios preferenciales.

- Subsidio al proceso de reubicación de los pobladores que no puedan permanecer en el area renovada.

- Castigo tributario a los sitios que permanezcan eriazos en las zonas a remodelar.

- Restricción de los usos de suelos, permitiendo sólo aquellos compatibles con el uso residencial.

- Mejoramiento del estándar de los servicios públicos de éstas, como forma de incentivar su desarrollo.

\section{Movilización habitacional:}

Una de las nuevas ideas en relación al tema habitacional es el que se relaciona con la denominada "movilización habitacional". Básicamente, mediante ella se permite que viviendas financiadas con subsidio, respecto de las cuales existe prohibición de 
venta por un período de tiempo, puedan ser entregadas en parte de pago por otras de un mayor valor, o en una ubicación geográfica distinta de la primitiva.

Se ha podido constatar que la rigidez respecto de la posibilidad de cambio de vivienda perjudica a los propietarios que deben cambiarse de ciudad o que están en condiciones de mejorar su vivienda por los aumentos en sus ingresos.

Esta alternativa se está comenzando a poner en práctica y, como toda iniciativa innovadora, necesita de la información pertinente a los usuarios.

\section{Concesiones:}

Un sistema relativamente nuevo en Chile es el implementado por la Ley de Concesiones; mediante ella se permite entregar a privados la construcción o ampliación de determinadas obras para que, a través de cobros a los usuarios, se obtengan las remuneraciones pertinentes al capital invertido.

En esta materia, se han entregado en concesión obras de gran importancia tales como la doble vía que une gran parte de Chile, (en la cual participan capitales mexicanos), puertos, aeropuertos y vialidad urbana.

\section{Proposiciones}

De lo anterior expuesto podemos concluir que el futuro desarrollo inmobiliario y del impacto positivo que éste tenga en el desarrollo del país, dependerá del perfeccionamiento que logremos incorporar al funcionamiento de sus mercados, para lo cual consideramos de primera importancia mejorar los aspectos normativos y reglamentarios, para lo cual será necesario:

- Mejorar en forma sustantiva la calidad de los instrumentos de planificación física, yendo más allá de la acotación de sus plazos de aprobación.

- Creemos positivo establecer formas reales de participación, de todos los sectores afectados, en la elaboración y aprobación de los Planes Reguladores, y que esta participación se dé desde las etapas de establecimiento de las líneas generales que orientan el desarrollo futuro de la Comuna, hasta las etapas de aprobación de la proposición de Plan.

Con este fin creemos importante informar responsablemente a la comunidad, mediante campañas de difusión, respecto del real valor de estos instrumentos y de cómo afectan directamente a cada persona y a cada actividad dentro de la comuna, lo que según nuestro parecer, incrementará el carácter positivo de dicha participación; pensamos que esta participación debería considerarse incluso en las formas de financiamiento de los estudios necesarios para la elaboración del plan.

Normalmente la elaboración de un Plan Regulador se financia sólo con recursos propios de la comuna, los que habitualmente son escasos y no corresponden en volumen a la importancia del trabajo a realizar. Esto se traduce en muchos casos en un 
contrato con limitación de recursos económicos, que pueden llegar a producir estudios incompletos y con un grado de superficialidad mayor del conveniente.

\section{4.- APOYO LEGAL Y ADMINISTRATIVO AL DERECHO DE PROPIEDAD}

Nuestro país sufrió durante los primeros setenta años del siglo pasado un deterioro paulatino del concepto relacionado con el derecho de propiedad, tendencia mundial en los países subdesarrollados y producto de ideas políticas mesianísticas.

Mirado desde una óptica actual, ese deterioro retrasó el crecimiento de nuestros países. Tal como lo hemos indicado anteriormente, un vuelco en esos conceptos fue dado a partir de la década de los setenta por el gobierno Militar que dirigió nuestro país, el que se ha mantenido en los gobiernos civiles que le sucedieron.

El cambio de mentalidad respecto del "derecho de propiedad", y los otros citados al comienzo de este trabajo significó crecimientos económicos importantes, sirviendo nuestro país de ejemplo a otros en materia de conducción económica; este crecimiento se tradujo en una indudable mejoría en los niveles individuales de ingresos de sectores importantes de la población.

El respeto a la "propiedad privada" se vio reflejado en nuestra Constitución Política del año 1980, Ley fundamental de toda nuestra organización jurídica en la cual se dio protección constitucional al derecho de propiedad en sus infinitas formas, desde el histórico, en sus diversas especies sobre toda clase de bienes corporales o incorporales, hasta la igualdad ante la ley en la protección de los derechos, el respeto y protección a la vida privada y pública, la inviolabilidad del hogar, la no discriminación arbitraria, etc.

Para proteger de manera eficiente esta normativa relacionada con el derecho a la propiedad y otros se creó, también con rango constitucional, el Recurso de Protección, destinado a amparar al que "por actos u omisiones arbitrarios o ilegales sufra privación, perturbación o amenaza en el legítimo ejercicio de determinadas garantías constitucionales".

El análisis legal del "negocio inmobiliario" implica conocer prácticamente toda la legislación chilena ya que, acorde con el tipo de negociación, puede aplicarse toda la normativa legal. De allí la importancia que atribuímos al "estudio de los títulos", ya que ello significa el análisis de los antecedentes necesarios para dar la "relativa" seguridad jurídica, no sólo a los inversionistas sino, además, a los adquirentes. Quisiéramos dar toda la información relativa a este tema en el presente esquema pero, de hecho, es imposible por lo extenso de ella.

De allí que, además de la normativa constitucional, que contempla las seguridades jurídicas necesarias, a través del reconocimiento explícito y la protección judicial al dominio, existen otras normas, de inferior rango, pero no menos importante que, o protegen la "propiedad" en igual sentido o norman los parámetros en que la actividad inmobiliaria puede y debe ejecutarse. 
Entre las normas generales que protegen a la propiedad se encuentran los códigos civil, de comercio, de minería y de aguas.

Entre las especiales, las leyes de Concesión, (ya comentada), eléctrica, de ban$\cos$, etc.

Especial importancia tiene la organización que entrega la seguridad administrativa a la actividad inmobiliaria. Promordialmente, pero no exclusivamente, esta seguridad está dada por el sistema de notarías, (dada por la presencia del ministro de fe), y por los conservadores, (que entregan la protección registral).

El legislador ha dado especial relevancia al tema de la corrección en el funcionamiento de estas dos instituciones de tal manera que sean pilares en la "fe pública".

Salvo situaciones excepcionalísimas, (que siempre se dan en la vida), el sistema funciona perfectamente.

Ambos sistemas están reglamentados en el Código Orgánico de Tribunales en atención a que notarios y conservadores son auxiliares de la administración de justicia.

Los notarios son funcionarios nombrados por el Estado, con la participación del Poder Judicial, que actúan como "ministros de fe pública encargados de autorizar y guardar en su archivo los instrumentos que ante ellos se otorgaren, dar a las partes interesadas los testimonios que pidieren y de practicar las demás diligencias que la ley les encomiende."

Existen, uno o más, en cada comuna o agrupación de comunas que constituya territorio jurisdiccional de jueces de letras.

Los conservadores son "los ministros de fe encargados de los registros conservatorios de bienes raíces, de comercio, de minas, de accionistas de sociedades propiamiente mineras, de asociaciones de canalistas, de prenda agraria, de prenda industrial, de especial de prenda y demás que le encomienden las leyes."

Existe uno en cada comuna o agrupación de comunas que constituya territorio jurisdiccional de jueces de letras.

Sin perjuicio de la presencia legal de estos funcionarios, existen otros ministros de fe para casos específicos como los oficiales del registro civil, el secretario de juzgado, el secretario de la oficina de impuestos internos y otros; asimismo, ciertos registros conservatorios, tales como el de vehículos motorizados, (entregado al Registro Civil), y el de protección a las marcas y propiedad intelectual, (al Ministerio de Economía).

Bien, con esta exposición he pretendido entregar un panorama muy general del desarrollo inmobiliario en nuestro país. Quisiera, y podría ser más extenso pero estimo que las omisiones y aclaraciones podrían servir para aclarar conceptos.

Estoy a vuestra disposición.

Muchas gracias. 